\title{
IMPLEMENTATION OF A SYSTEMATIC MATERIALS SELECTION METHOD IN THE PRELIMINARY DESIGN OF PROPELLER SHAFTS
}

\author{
Liane Roldo, Nenad Vulić \\ University of Split (Croatia)
}

\begin{abstract}
The materials selection charts also known as "Ashby" charts are a versatile tool in engineering design. The use of such material property charts is due to technical difficulties in specifying properties during the design of a complex and major component as in the case of a propeller shaft. In addition, the tool combines innovation, minimizes design failures and practicality to technology. The aim of the research is to present the methodology for selecting the most convenient material for a given shaft and its performance. Using a propeller shaft as showcase, the method is based on the analysis of the materials selection charts and of the material performance index of EDUPACK from GRANTA Design. The required properties may be: tensile strength, yield strength, fatigue strength, impact strength and resistance to corrosion, where not all of them are necessarily explicitly expressed. The Ashby charts, with their consistent results seem to be the proper tool for the eventual future proposal for the extension the UR M68 formula for the propeller shaft diameter to stainless steels.

Keywords: main propulsion shafting; tensile strength; fatigue strength; dimensioning
\end{abstract}

\section{Introduction}

Propeller shaft shall withstand the static and dynamic loading of the shafting system. The dynamic loading is caused by several sources of vibrational excitation, causing torsional, axial, flexural, as well as whirling vibrations of the entire shafting system.

At an early design phase, it is impossible to cope with all of these loadings, because there are little data known about the actual shafting. The designer has just selected the shafting construction shape on a conceptual level only, having only the maximal continuous rated (MCR) power and the referent rotational speed (rpm) available, still having to select the material for the propeller shaft. The next immediate step would be to calculate the propeller shaft diameter based upon the MCR, rpm and fatigue strength of material. The common practice is to use a simple formula from the IACS Unified Requirement UR M68 ${ }^{1)}$, as implemented within the technical rules of the actual classification society, e.g. ${ }^{2}$. 
The aim of this paper is to propose a possible way that may be implemented to extend that formula to the wider range of steels, such as stainless high-alloyed chemically resistant steels, e.g. AISI 403, AISI 316, AISI 316L, or similar, with the help of the material selection tool as available in EDUPACK from GRANTA Design. This is important because these types of steels are extensively used in the growing fleet of Croatian tourist ships for one-day-trips and Croatian small cruisers for coastal service with their tonnage below 500 GT. The ship owners and the designers of such ships prefer the mentioned stainless steels for their propeller shafts over any other type of steel. The method to perform this task is based on the analysis of the materials selection charts (Ashby charts) and the implementation of the material performance index of Granta EduPack.

\section{Problem formulation}

The designer takes the rules for the classification of ships of the IACS classification society classing the ship, e.g. ${ }^{1)}$, knowing that the prescribed approach to determine this diameter in these rules is based upon the IACS Unified Requirement UR M68 ${ }^{2}$. There are no other means to determine the shaft diameter in this design starting phase because nothing else has been currently defined yet. This means that the propeller shaft's total length, as well as the lengths of its parts are not yet known, though the static and dynamic behavior and the response of the propulsion shafting system (weight, mass distribution, stiffness, damping, etc.) significantly depend upon these for now unknown values. Consequently, the value of the material property, representing the actual torsional strength has to be reduced by an amount large enough that the minimal diameter cover also axial stress (due to the thrust force), bending (due to weight and point forces and moments transmitted to the shaft), as well as the influence of repetitive stresses causing fatigue.

The actual approach from the Unified Requirement UR M68 2 is briefly described hereafter.

Propeller shaft diameter is not to be less than the one determined from the next unit dependent formula:

$$
d_{\min }=F \cdot k \sqrt[3]{\frac{P}{n} \cdot \frac{1}{1-\left(\frac{d_{i}}{d_{o}}\right)^{4}} \cdot \frac{560}{\sigma_{B}+160}}
$$

where:

$d_{\min }$ - required min. shaft diameter, mm

$F$ - factor for type of propulsion installation

$F=100$ for all propeller shafts.

$k$ - factor for the particular shaft design features 
$k=1,26$ for key fitted propellers,

$k=1,22$ for flange mounted or keyless taper fitted propellers,

$k=1,15$ for propeller shaft parts between forward end of aft most bearing and forward stern tube seal.

$d_{i}$ - actual diameter of shaft bore (may be neglected when $d_{i} \leq 0,4 d_{o}$ ), $\mathrm{mm}$

$d_{0}$ - actual outside diameter of shaft, $\mathrm{mm}$

$P$ - rated power transmitted through the propeller shaft (losses in gearboxes and bearings are to be disregarded), $\mathrm{kW}$

$n$ - shaft speed at rated power, rpm

$\sigma_{B}-$ specified minimum tensile strength of the propeller shaft material, $\mathrm{N} / \mathrm{mm}^{2}$

The limitation is imposed to the value of the specified minimum tensile strength, so that in general for propeller shafts $\sigma_{B}$ in the formula is not to exceed $600 \mathrm{~N} / \mathrm{mm}^{2}$ (for carbon, carbon manganese and low-alloy steels). Where materials with greater specified or actual tensile strengths than the given limitation are used, reduced shaft dimensions are not acceptable if they originate from the formula unless it is verified that the material exhibits similar fatigue life as conventional steels.

However, the unified requirement ${ }^{2}$ does not specify anything with respect to the implementation of stainless high-alloyed chemically resistant steels for the propeller shafts, regardless of the fact that they are, by the authors' experience, today most commonly used in practice in small tourist one-day-trip ships and small cruisers of coastal service.

An example of the propulsion system components for a ship of the mentioned type and service has been given in figures 1 to 3 . Figure 1 presents the propulsion shafting system layout arrangement for such a small ship in national coastal service. Figure 2 presents the assembly drawing of the propeller shaft, whereas the Figure 3 presents the relevant stern tube arrangement, showing also that the aft stern tube end is open allowing sea-water to enter freely, forming lubrication emulsion with grease that is already in the stern tube.

In the case presented in these figures, the actual propeller shaft material is stainless steel AISI 316L. The outer stern tube is made of carbon steel. The aft and fore stern tube bearings are made of thin white metal layer on bronze CuSn14 thick tubes.

\section{Methods}

The essential idea to approach the solution to the formulated problem is to correlate the material fatigue strength implicitly imposed in the formula (1) with its explicitly specified tensile strength $\sigma_{B}$ within the same formula for the steels that the formula may be directly applied to (carbon, carbon manganese and low alloy steels). After that the same correlation shall be applied to stainless steels, bearing in mind that the equal fatigue strength for the two materials would mean their equivalence in this sense, where low-cycle fatigue is the actual mechanism of their possible failure. 


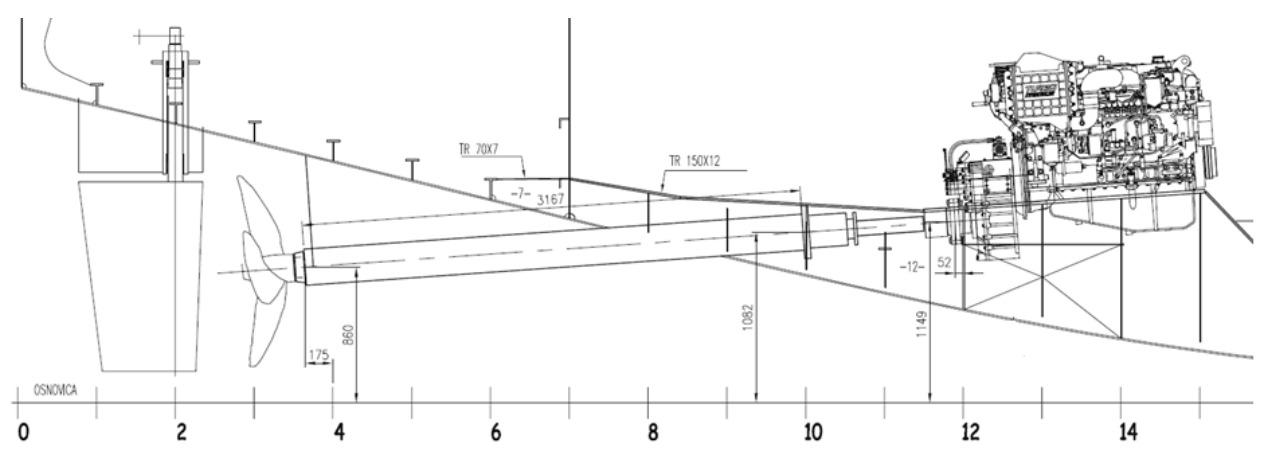

Figure 1. Scheme of the small passenger ship rear structure with the layout of the main propulsion shafting system with 4-stroke Diesel engine and reduction gearbox

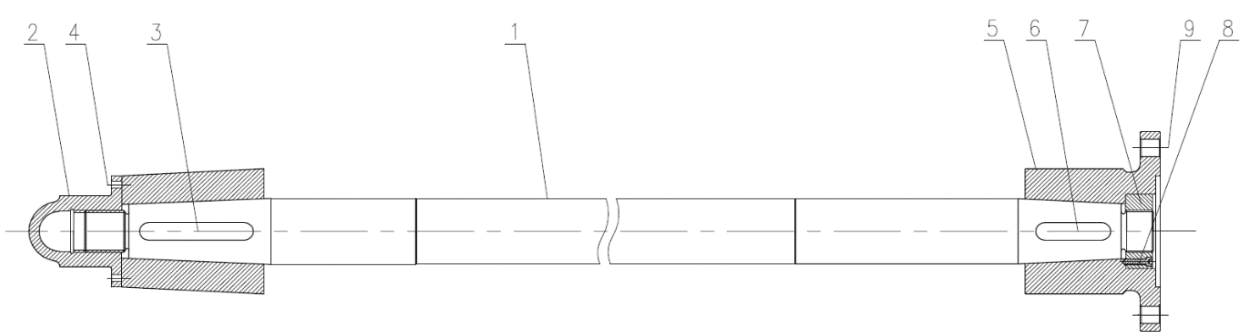

Figure 2. Propeller shaft assembly of the small passenger ship: 1 - AISI 316L stainless-steel propeller shaft, 2 - bronze propeller cap with nut, 3 - stainless steel key, 4 - stainless-steel bolts, 5 - carbon steel coupling, 6 - carbon steel key, 7 - carbon steel coupling nut, 8 - carbon steel pin, 9 - carbon steel coupling bolts.

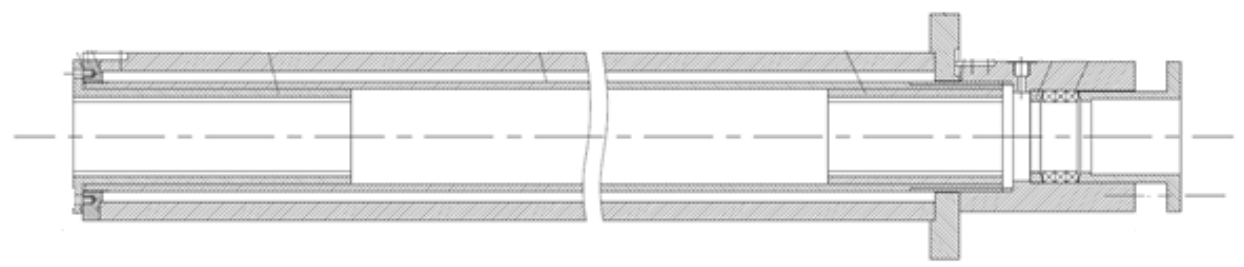

Figure 3. Schematic drawing showing the stern tube assembly of the small passenger ship

\section{Results and discussion}

To achieve the stated goal the essential mechanical properties necessary for this analysis were taken out from the Ashby charts obtained by means of the Granta 
EduPack software, as well as from the tables available in (Kulenović et al. 2020; Wittel et al. 2009) ${ }^{3)}$. Table 1 contains the selected carbon, carbon manganese and lowalloy steels, as well as selected stainless steels normally used for the manufacturing of propeller shafts, together with their selected mechanical properties, i.e. tensile strength, yield strength and fatigue strength due to axial alternating load. Granta EduPack showed itself very useful to judge whether the material would be convenient regarding its chemical composition for this application.

Table 1. Mechanical properties of selected steels ${ }^{4)}$

\begin{tabular}{|l|l|l|l|l|l|}
\hline $\begin{array}{l}\text { Propeller shaft } \\
\text { material types } \\
\mathbf{l}^{*} \text { stainless steel) } \\
\text { AISI-SAE }\end{array}$ & $\begin{array}{l}\text { Unified } \\
\text { Numbering } \\
\text { System } \\
\text { UNS }\end{array}$ & $\begin{array}{l}\text { Tensile } \\
\text { strength } \\
R_{m, N} \\
\mathrm{~N} / \mathrm{mm}^{2}\end{array}$ & $\begin{array}{l}\text { Yield } \\
\text { strength } \\
\mathrm{R}_{\mathrm{p}, \mathrm{N}} \\
\mathrm{N} / \mathrm{mm}^{2}\end{array}$ & $\begin{array}{l}\text { Fatigue } \\
\text { strength } \\
\text { axial } \\
\sigma_{D-1, v, N} \\
\mathrm{~N} / \mathrm{mm}^{2}\end{array}$ & $\begin{array}{l}\text { Temper } \\
\text { designations }\end{array}$ \\
\hline $403^{*}$ & $\mathrm{~S} 40300$ & $420-690$ & $245-550$ & $233-331$ & annealed \\
\hline $316 \mathrm{~L}^{*}$ & $\mathrm{~S} 31603$ & $480-620$ & $170-310$ & $256-307$ & wrought \\
\hline 1015 & $\mathrm{G} 10150$ & $380-470$ & $300-355$ & $217-253$ & normalized \\
\hline 1020 & $\mathrm{G} 10200$ & $395-490$ & $310-350$ & $223-260$ & normalized \\
\hline 1022 & $\mathrm{G} 10220$ & $430-535$ & $320-395$ & $237-277$ & normalized \\
\hline 1117 & $\mathrm{G} 11170$ & $415-520$ & $270-335$ & $231-271$ & normalized \\
\hline 1118 & $\mathrm{G} 11180$ & $425-530$ & $285-355$ & $235-275$ & normalized \\
\hline
\end{tabular}

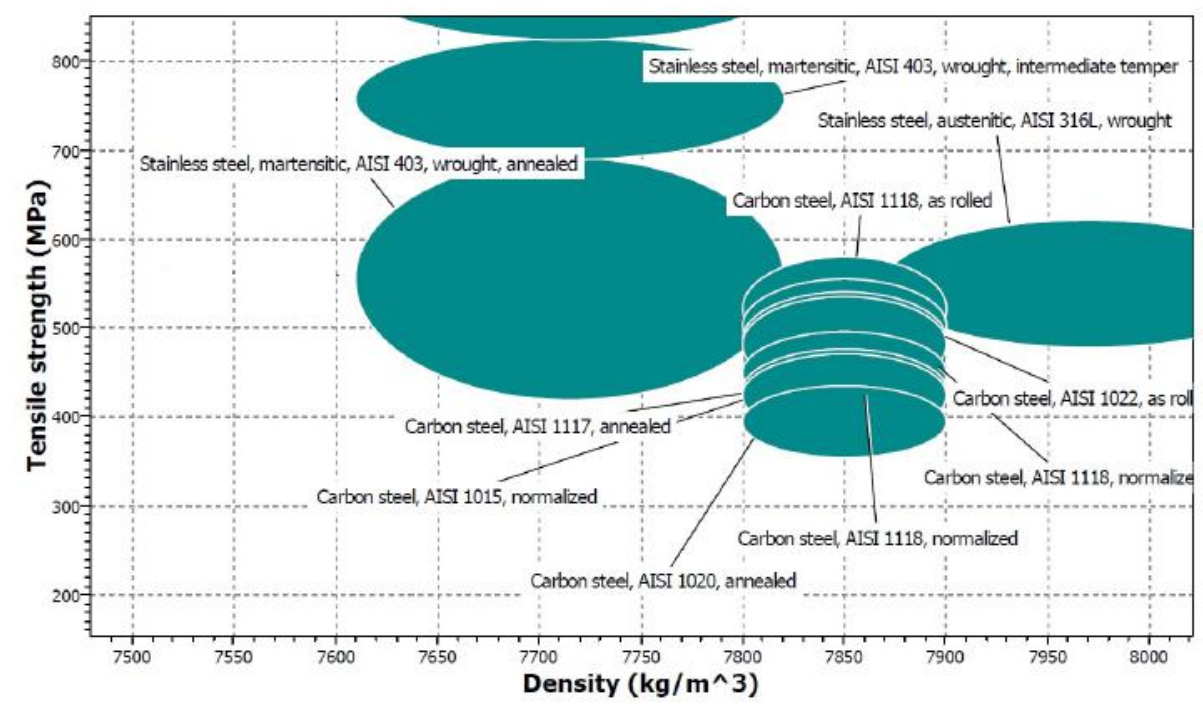

Figure 4. Ashby plot illustrating the tensile strength against the density of the selected steels 


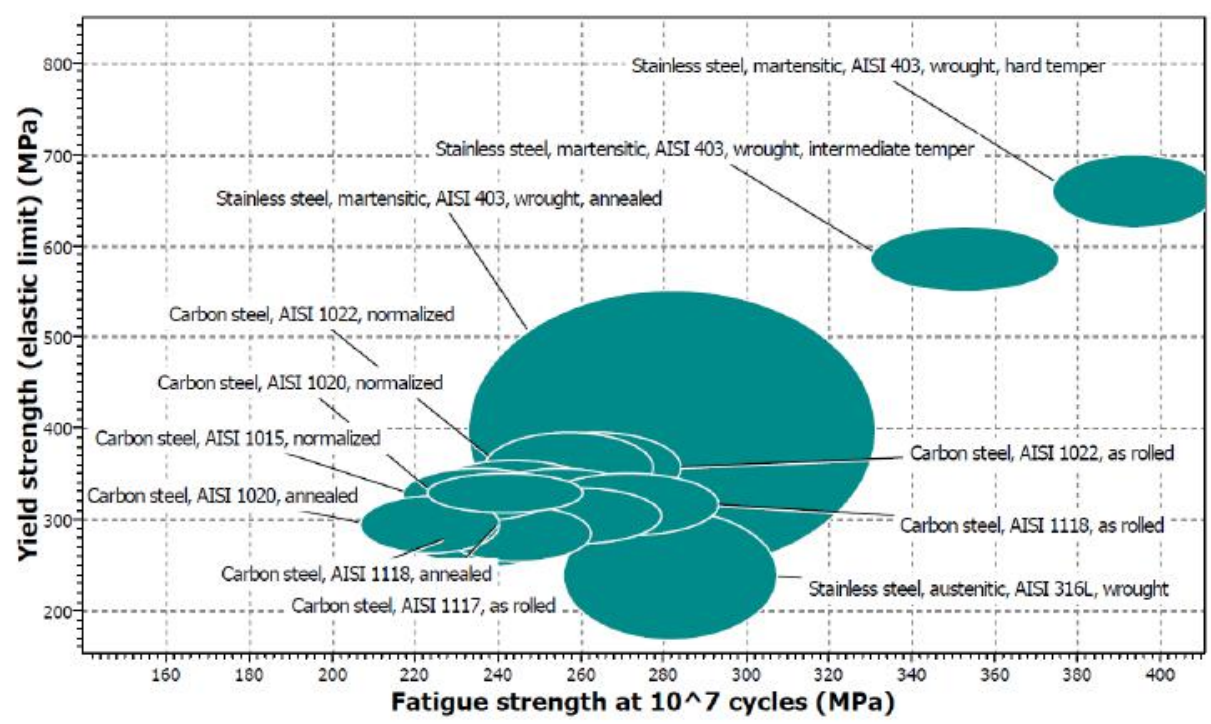

Figure 5. Yield strength plotted against fatigue strength at $10^{7}$ cycles.

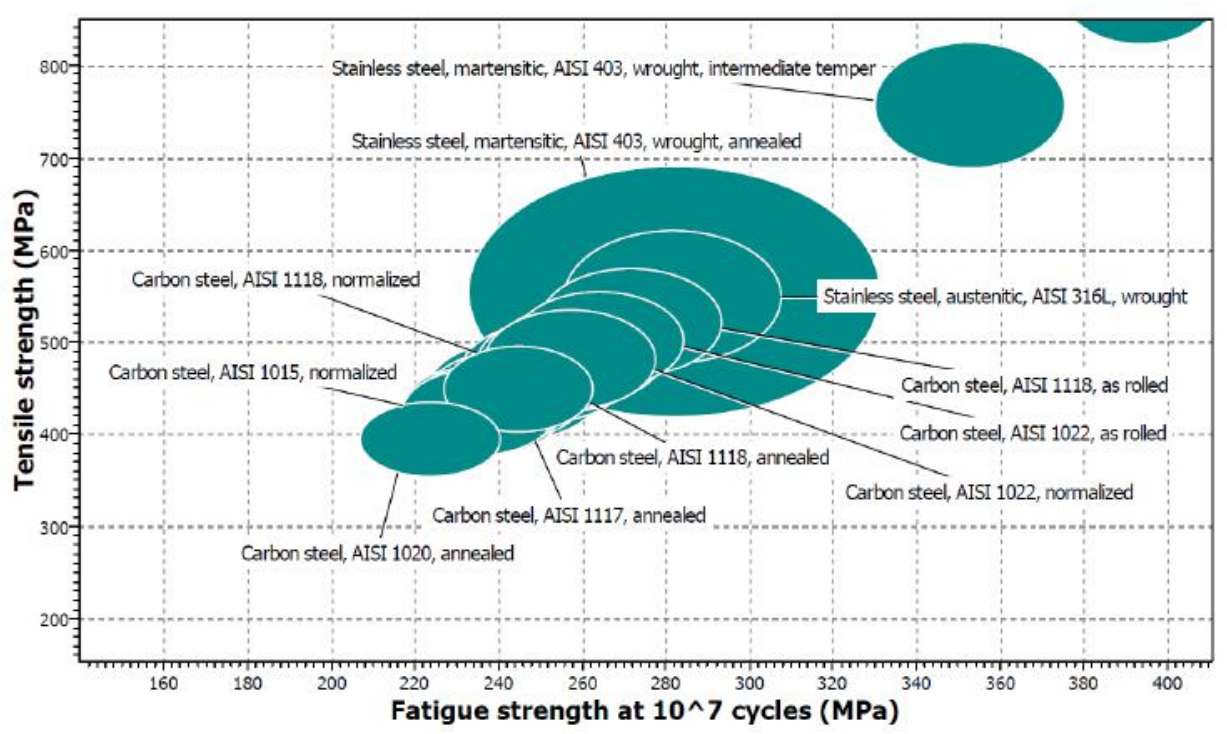

Figure 6. Tensile strength plotted against fatigue strength at $10^{7}$ cycles. The carbon steel, AISI 1015 is according to Granta EduPack the equivalent of DIN St 37-2. 
Given the conceptual layout of the main propulsion shafting, the main engine maximal continuous rated power, and the relevant rotational speed, the designer of the propeller shaft shall determine its minimal required diameter taking into account the tensile strength of the shafting material as the only practically known property of the material in question.

The starting point to use the Granta charts was the carbon steel DIN St 37-2 (equivalent AISI 1015) normally used for forged parts such as shafts. The relevant physical property to compare the properties of candidate materials is its density. The relevant mechanical properties of the candidate materials are tensile strength, yield strength and fatigue strength.

Based upon these properties other materials were selected by the Ashby charts to be presented as possible candidate materials for propeller shafts in the two design concepts (Ashby 2011).

In the concept of carbon steel propeller shaft materials with a carbon content between $0.15-0.20 \%$, manganese content between $0.3-1.6 \%$ weight, AISI 1015, AISI 1020, AISI 1117 and AISI 1118 show to be proper choice. The two stainless steels, namely martensitic AISI 403 (C 0.15\% max, Mn 1\% max, Cr $11.5-13 \%$ wt.) and austenitic AISI 316L (C 0.03\% max, Mn 2\% max, Cr 16-18, Ni $10-14 \%$, Mo $2-3 \% \mathrm{wt}$.) are the ones to be adjusted by some of their properties, so that to find the way to apply the formula (1) to these materials. The actual value of this adjustment for a certain material is yet to be determined.

\section{Conclusions}

Evaluation of the minimal diameter of the propeller shaft is necessary in the earliest phase of designing of any ship propulsion shafting system. It is normally based upon the formula (1). The formula is based upon the low-cycle fatigue strength of the shaft and takes into account only the shaft power, its nominal rotational speed, tensile strength of the shaft material, as well as the position of the section within the shaft. Unfortunately, this formula can be applied only to the carbon, carbon manganese and low-alloy steels.

Many propeller shafts of modern ships are made of stainless steels, so that a direct implementation of formula (1) to this type of material is ambiguous. This paper presents the helpful material selection tool of Granta Design that is expected to be implemented in possible future amendment of the calculation formula to cover the stainless steels, as well as for the verification of the eventual new proposal.

Within the process of preparing the final formula, the materials selection charts and implementation of Granta EduPack software in the final verification are expected to be useful and practical tools. The paper also wants to promote the use of such software tools in the cases when some deeper facts about material properties are to be taken into account in developing technical procedures such as the one presented. 


\section{NOTES}

1. Rules for the Classification of Ships, Part 7-Machinery Installation, Croatian Register of Shipping. Split, 2020.

2. Unified Requirement UR M68 Dimensions of propulsion shafts and their permissible torsional vibration stresses, Rev 2, International Association of Classification Societies. London, 2015.

3. FKM Guideline: Analytical Strength Assessment of Components, Made of Steel, Cast Iron and Aluminum Materials in Mechanical Engineering (6th Edition, VDMA Verband Deutscher Maschinen- und Anlagenbau. Berlin, 2012

4. Granta EduPack materials selection software, 2013.

\section{REFERENCES}

Kulenović, Z., Vulić, N., 2020. Elements of ship machinery and maritime structures. Split: Faculty of Maritime Studies-University of Split [in Croatian].

Wittel, H. et al, 2009. Roloff/Matek Maschinenelemente-Tabellenbuch (19. Auflage). Wiesbaden: Vieweg + Teubner Verlag.

Ashby, M. F., 2011. Materials Selection in Mechanical Design. Burlington: Elsevier Ltd., $4^{\text {th }}$ Edition.

$\square$ Liane Roldo
ORCID iD: 0000-0002-0301-8631
Nenad Vulić

Web of Science Researcher ID: D-7523-2017

Faculty of Maritime Studies

University of Split Split, Croatia

E-mail: 1roldo@pfst.hr

E-mail: nvulic@pfst.hr 